\title{
Pengaruh Instagram Sebagai Social Media Marketing Terhadap Perilaku Konsumtif Wanita Karir Di Kota Pekanbaru
}

\author{
Nurrahmi Hayani \\ UIN Sultan Syarif Kasim Riau \\ Email: nurrahmi.hayani@uin-suska.ac.id \\ Muhammad Ikbal \\ UIN Sultan Syarif Kasim Riau \\ Email:mr.maulana34@yahoo.co.id
}

\begin{abstract}
The purpose of this study was to determine the effect of Instagram as social media marketing on consumer behavior. The population in this study were all career women in Pekanbaru with an age range of 17 to 45 years and had used Instagram as a medium for shopping or reference before making a product purchase. The sampling method in this study uses non random sampling with a purposive sampling technique. The data used are primary data and secondary data. The data analysis method used is a simple linear regression method. The results showed that Instagram as social media marketing had a significant effect on the consumptive behavior of career women in the city of Pekanbaru. The influence of Instagram as social media marketing on the consumptive behavior of career women in the city of Pekanbaru is shown by a coefficient of determination of 0.563. This shows that $56.3 \%$ of consumer behavior is influenced by social media marketing and the remaining $43.7 \%$ is influenced by other variables not used in this study.
\end{abstract}

Keywords: instagram, social media marketing, consumptive behavior

\begin{abstract}
Abstrak
Penelitian ini bertujuan untuk mengetahui pengaruh Instagram sebagai social media marketing terhadap perilaku konsumtif. Adapun populasi dalam penelitian ini adalah seluruh wanita karir di Kota Pekanbaru dengan rentang usia 17 hingga 45 tahun yang menggunakan Instagram sebagai salah satu media untuk berbelanja atau referensi sebelum melakukan pembelian suatu produk . Metode pengambilan sampel dalam penelitian ini menggunakan nonrandom sampling dengan teknik purposive sampling dimana teknik ini mengambil sampling dengan pertimbangan tertentu. Data yang digunakan adalah data primer dan data sekunder. Metode analisis data yang digunakan adalah metode regresi linear sederhana. Hasil penelitian menunjukkan bahwa Instagram sebagai social media marketing berpengaruh signifikan terhadap perilaku konsumtif wanita karir di kota Pekanbaru. Besar pengaruh Instagram sebagai social media marketing terhadap perilaku konsumtif wanita karir di kota Pekanbaru ditunjukkan dengan koefisien determinasi sebesar 0,563. Hal ini menunjukkan bahwa 56,3\% Perilaku konsumtif di pengaruhi oleh social media marketing dan sisanya sebesar 43,7\% dipengaruhi oleh variabel lain yang tidak digunakan dalam penelitian ini.
\end{abstract}

Kata kunci: instagram, social media marketing dan perilaku konsumtif 


\section{Pendahuluan}

Perkembangan teknologi informasi dan komunikasi begitu pesat semenjak kemunculan internet khususnya media sosial. Media sosial merupakan perkembangan mutakhir dari teknologi-teknologi web baru berbasis internet, yang memudahkan semua orang untuk dapat berkomunikasi, berpartisipasi, saling berbagi dan membentuk sebuah jaringan secara online, sehingga dapat menyebar luaskan konten mereka sendiri. post di blog, tweet atau video youtube dapat diproduksi dan dimanfaatkan sebagai sarana pemasaran secara langsung oleh jutaan orang secara gratis (Zarella, 2010).

Instagram menjadi salah satu sarana yang bisa dimanfaatkan untuk kegiatan pemasaran melalui media sosial, dengan jumlah pengguna aktif menurut hasil survei www.statista.com mencapai 1 miliar orang di dunia dan lebih kurang 62 juta orang di Indonesia. Masyarakat dengan mudah dapat mengunggah produk yang ingin dijual pada akun yang ia miliki lebih cepat dan tanpa harus mengeluarkan biaya. Di samping itu, Instagram juga selalu digunakan konsumen untuk mencari barang-barang yang ia inginkan atau untuk memenuhi kebutuhannya. Berdasarkan data statistik platform media sosial yang digunakan oleh pemasar di seluruh dunia pada januari 2018 menunjukkan bahwa Instagram menempati posisi ke dua setelah Facebook, dengan persentase 66\%, sebanyak 3.762 responden menyatakan bahwa ia menggunakan Instagram untuk memasarkan bisnisnya, dari total 5.700 responden yang berpartisipasi. Berikut adalah beberapa data pengguanaan Instagram dan pemanfaatannya di dunia internasional:

Gambar 1.1. Sosial Media Berdasarkan Jumlah Pengguna Terbanyak Hingga Tahun 2019 (Dalam Jutaan)

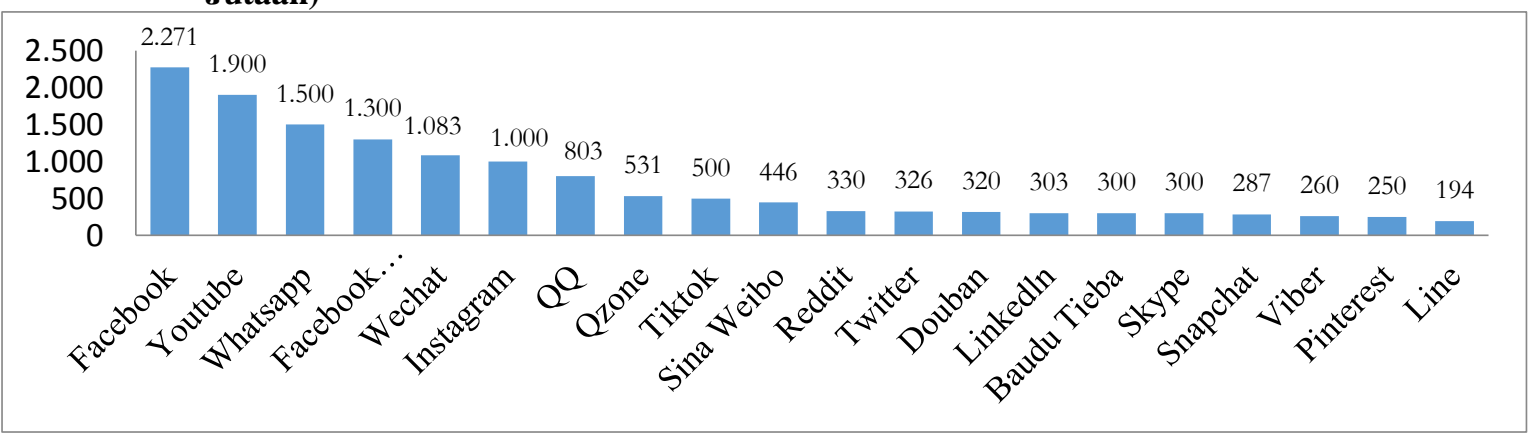

Sumber : www.statista.com 2019

Gambar diatas menunjukkan bahwa hingga tahun 2019, media sosial Facebook berada di posisi paling atas untuk kategori sosial media yang paling banyak digunakan di dunia internasional dan Instagram menempati tempat ke-6 dengan total jumlah pengguna hingga tahun 2019 sebanyak 1 juta pengguna. 


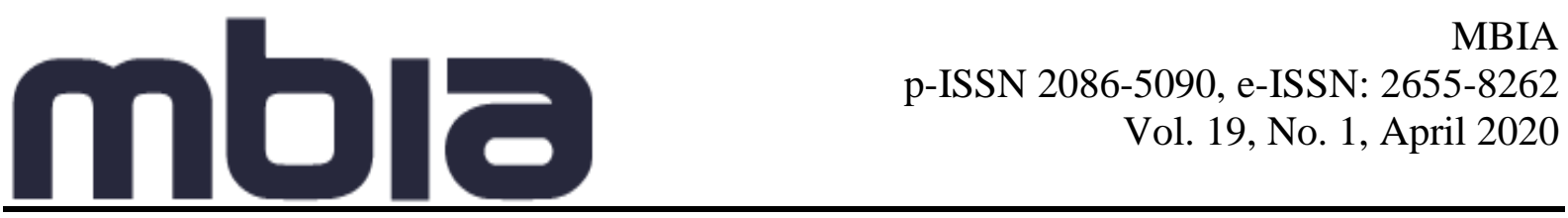

Gambar 1.2. Jumlah Pengguna Instagram Berdasarkan Negara di Tahun 2019 (Dalam Jutaan)

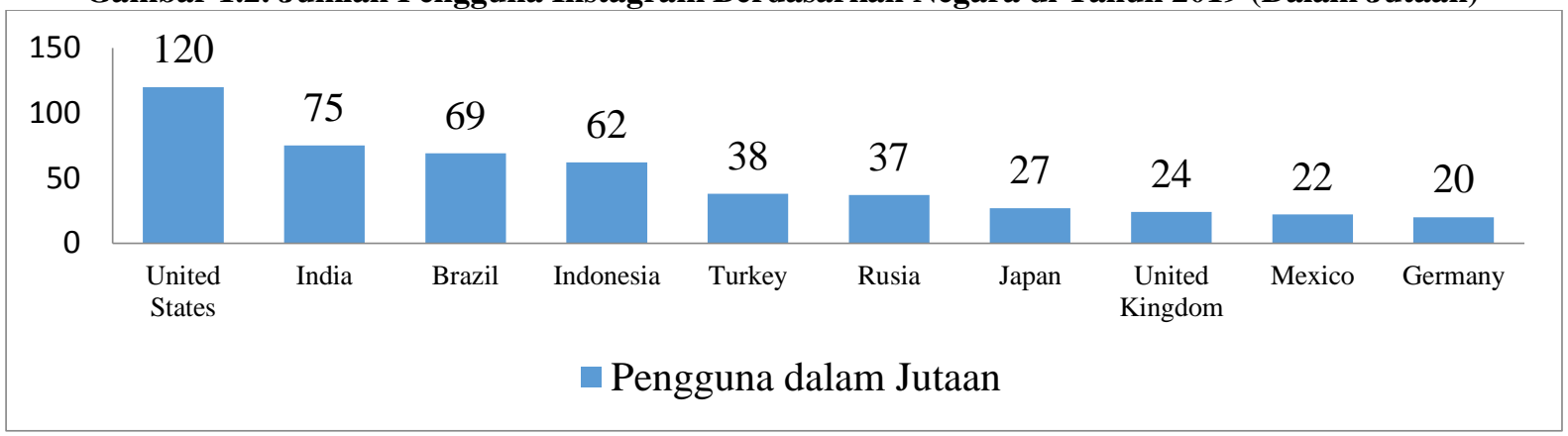

Sumber : www.statista.com 2019

Dari Januari 2013 hingga Juni 2019 pengguna Instagram diseluruh dunia mengalami peningkatan yang signifikan, yaitu dari 90 juta pengguna hingga pada akhir Juni 2018 mencapai 1 Milyar lebih pengguna, yang artinya media sosial ini sangat diterima oleh masyarakat dan tentunya pemasar harus melihat peluang tersebut. Dari sekian banyaknya pengguna Instagram tersebut, Indonesia menjadi negara diposisi ke-4 pengguna terbanyak dengan total 62 juta pengguna diikuti oleh Turki, Rusia dan Jepang.

Dari data diatas terlihat jelas bahwa Instagram menjadi salah satu media sosial yang sangat digandrungi oleh masyarakat saat ini, tentunya peluang tersebut telah dilihat dan dimanfaatkan oleh perusahaan-perusahaan maupun individu untuk menjadikan Instagram sebagai salah satu saluran pemasaran untuk memasarkan produknya, karena jika dilihat dari tren saat ini media sosial menjadi media yang sangat efektif untuk dijadikan saluran pemasaran atau istilah lainnya social media marketing.

Sama dengan media sosial lainnya Instagram sebagai social media marketing dalam aplikasinya juga bergantung pada empat indikator penting dalam bauran pemasaran atau marketing mix, yang meliputi product (produk), price (harga), place (distribusi) dan promotion (promosi) (Barnes, 2015).

Munculnya fenomena pemasaran online yang dilakukan oleh para pengguna berbagai media sosial seperti Instagram, menandakan bahwa semakin beragamnya jenis kebutuhan dari para calon konsumen dan terdapat adanya budaya konsumtif dalam masyarakat khususnya orang dewasa yang paling banyak mendominasi penggunaan situs jejaring sosial Instagram. Hal tersebut menandakan masuknya masyarakat Indonesia khususnya kalangan dewasa ke dalam arus globalisasi dimana sebagian besar dari mereka melakukan segala bentuk transaksi secara daring, dan hal ini juga dapat menandakan bahwa menurunnya tingkat kesadaran dan kekurang mampuan dalam mengurai segala jenis kebutuhan yang sekiranya memang menjadi bagian dalam kehidupan sehari-hari, hingga pada akhirnya mereka memiliki perilaku konsumtif.

Perilaku konsumtif adalah suatu perilaku pembelian yang tidak lagi didasarkan atas kebutuhan atau pertimbangan yang rasional, melainkan membeli produk atau jasa tertentu untuk memperoleh kesenangan semata atau untuk tujuan gengsi dan menaikkan status sosial (Sumartono, 2002). Baudrillard (2017) menyatakan bahwa perilaku konsumsi saat ini tidak hanya dipengaruhi oleh faktor-faktor ekonomis (pendapatan) dan berdasar pada pilihanpilihan rasional akan tetapi juga terdapat sistem budaya (kondisi lingkungan) dan sistem pemaknaan sosial (gaya hidup bermasyarakat). Meskipun beragam, namun pada intinya 
pengertian perilaku konsumtif adalah membeli barang tanpa pertimbangan rasional atau bukan atas dasar kebutuhan pokok.

Perilaku konsumtif saat ini banyak ditemukan pada berbagai macam status sosial masyarakat. Baik dari kalangan pengusaha, PNS, pelajar, pria maupun wanita. Diantara status yang rentan terkena perilaku konsumtif adalah wanita karir. Wanita karir adalah wanita yang menekuni sesuatu atau beberapa pekerjaan dengan dilandasi keahlian tertentu yang dimilikinya untuk mencapai suatu kemajuan dalam hidup. Dalam menjalankan status sosialnya, wanita karir kerap dituntut untuk dapat menyesuaikan diri dengan lingkungan sosialnya. Untuk itu wanita karir perlu memenuhi kebutuhan hidupnya guna penyesuaian diri terhadap lingkungan sosial tersebut. Baik dari segi penampilan maupun dari segi sarana prasana penunjang kerja.

Dalam pemenuhan kebutuhan tersebut, terkadang wanita sering tergoda untuk berpenampilan yang lebih menarik dibandingkan dengan orang lain. Untuk itu wanita karir sering membeli sesuatu yang tidak sesuai dengan kebutuhannya. Keinginan untuk membeli sesuatu ini biasa muncul dikarenakan melihat iklan suatu produk di televisi, sosial media, ataupun media komunikasi lainnya dengan rayuan-rayuan iklan yang diberikan, ikut-ikutan teman yang mengikuti mode yang sedang berkembang, dan seringkali mementingkan gengsinya agar tidak ketinggalan zaman. Misalnya membeli tas, baju, atau sepatu untuk aktivitas kerja atau santai padahal mereka sudah memiliki barang tersebut dengan jumlah yang banyak dirumah. Hal ini menggambarkan bahwa perilaku konsumtif merupakan perilaku yang tidak perlu dipupuk dalam diri manusia.

Beberapa wanita punya kecenderungan untuk kompulsif sehingga ketika belanja tidak bisa fokus pada satu pilihan, dan penyebab lainnya wanita lebih berpotensi untuk berperilaku konsumtif dibandingkan pria diungkapkan dalam penelitian yang dilakukan oleh ilmuwan di University of Michigan School of Public Health. Seperti dikutip dari Discovery News. Dalam penelitian itu terungkap perbedaan perilaku belanja antara pria dan wanita sudah terlihat sejak zaman nenek moyang di masa berburu (Yuliastra, 2013).

\section{Landasan Teori}

\subsection{Social Media Marketing}

Pemasaran media sosial atau sering disebut social media marketing adalah bentuk pemasaran langsung atau tidak langsung yang digunakan untuk membangun kesadaran, pengakuan, ingat, dan tindakan untuk merek, bisnis, produk, orang, atau badan lain dan dilakukan dengan menggunakan alat-alat dari web sosial, seperti sebagai berbagi blogging, mikrobloging, jejaring sosial, bookmark social dan konten. Social media marketing mencakup taktik tertentu seperti berbagi kupon atau mengumumkan penjualan di facebook atau twitter, atau bisa mencakup lebih luas membangun merek inisiatif seperti berkomunikasi dengan orang-orang atau menciptakan konten yang menarik di blog, dalam sebuah video yang diunggah ke Youtube atau dalam presentasi bersama berbagi slide. Selain itu, pemasaran media sosial menawarkan kesempatan besar untuk pengusaha, usaha kecil, perusahaan menengah, dan perusahaan besar untuk membangun merek mereka dan bisnis mereka (Gunelius, 2011).

Gunelius menyatakan bahwa tujuan paling umum dari pemasaran media sosial adalah sebagai berikut: 
1. Membangun hubungan. Manfaat utama dari pemasaran media sosial adalah kemampuan untuk membangun hubungan dengan konsumen secara aktif.

2. Membangun merek. Percakapan melalui media sosial menyajikan cara sempurna untuk meningkatkan brand awareness, meningkatkan pengenalan dan ingatan akan merek dan meningkatkan loyalitas merek.

3. Publisitas. Pemasaran melalui media sosial menyediakan outlet di mana perusahaan dapat berbagi informasi penting dan memodifikasi persepsi negatif.

4. Promosi. Melalui pemasaran media sosial, memberikan diskon eksklusif dan peluang untuk audiens untuk membuat orang-orang merasa dihargai dan khusus, serta untuk memenuhi tujuan jangka pendek.

5. Riset pasar. Menggunakan alat-alat dari web sosial untuk belajar tentang pelanggan, membuat profil demografi dan perilaku pelanggan, belajar tentang keinginan dan kebutuhan konsumen, serta belajar tentang pesaing.

Menurut Gurnelius (2011), terdapat empat pilar pemasaran media sosial yaitu :

1. Membaca. Pemasaran melalui media sosial dimulai dengan penelitian, dan penelitian yang harus berkelanjutan. Pemasaran melalui media sosial membutuhkan banyak membaca. Tidak hanya tinggal pada apa yang terjadi dalam industri, tetapi juga perlu disadari dari percakapan online yang sedang berlangsung terjadi hubungan dengan industri, produk, layanan, pelanggan, dan pesaing. Membaca dalam berbagai bentuk untuk mencerna informasi sebanyak yang berhubungan dengan bisnis sehingga secara efektif dapat berkomunikasi dengan baik.

2. Membuat. Buat dan terbitkan konten online yang berguna dan bermakna. Sukses dalam pemasaran media sosial berasal dari mengembangkan percakapan online tentang bisnis, merek, produk, dan promosi dengan menawarkan konten yang menarik minat target audiens.

3. Share (bagikan). Aspek unik dari pemasaran media sosial adalah berbagi konten sebagai metode untuk langsung memasarkan bisnis. Pada saat sekarang konsumen telah bergantung pada hubungan, ulasan, rekomendasi, dan percakapan sehingga dapat dimanfaatkan untuk berbagi informasi dengan berbagi konten online. Berbagi konten dapat dalam dua bentuk utama. Pertama, berbagi konten yang menarik dan berguna ditemukan secara online selama membaca (pilar pertama). Dengan menemukan posting blog yang diisi dengan tips dapat membantu pelanggan. Kedua, berbagi konten yang dibuat (pilar kedua). Misalnya, meng-upload presentasi melalui slides-hare, video di Youtube, dan gambar di Flickr. Berbagi konten sendiri untuk mempublikasikan secara online melalui berbagai alat media sosial. Mempublikasikan sebuah posting di blog, berbagi melalui twitter, melalui social bookmark, melalui jejaring sosial. Tujuannya adalah berbagi konten ke khalayak yang lebih luas.

4. Diskusikan. Ketika konsumen berinteraksi dengan pemasar dengan meninggalkan komentar di salah satu posting blog, terhubung dengan pemasar melalui twitter atau jejaring sosial, sangat penting ditanggapi oleh perusahaan. Tidak ada yang suka diabaikan, tapi semua orang suka menjadi pengetahuan positif. Dengan kata lain, menunjukkan bahwa perusahaan menghargai, menghormati pendapat, dan ingin membangun hubungan dengan konsumen. Memberikan informasi yang berguna dan berinteraksi menjadi kepribadian semua elemen penting dari keberhasilan media sosial, tapi hal ini belum cukup. Perusahaan juga harus dapat diakses, yang berarti perlu untuk mengelilingi audiens, sehingga orang dapat memilih di mana pelanggan merasa nyaman terlibat dengan perusahaan. Tidak semua konsumen suka membaca blog, juga tidak semua konsumen suka 
membaca update twitter. Perusahaan perlu melakukan beberapa penelitian saat memulai perjalanan web sosial dan mencari tahu di mana pelanggan berada sehingga dapat bergabung dengan percakapan dan mulai mempublikasikan merek perusahaan.

Instagram sebagai social media marketing bisa mempengaruhi sikap dan perilaku konsumen hingga pada akhirnya menimbulkan perilaku konsumtif dimana pengguna Instagram tersebut membeli barang dengan tujuan bukan untuk memenuhi kebutuhan semata, melainkan untuk menunjukkan identitas diri mereka agar bisa diterima oleh lingkungannya, menaikkan gengsi, prestise dan untuk tampil beda dari lingkungannya (Boer, 2014), (Scheinbaum, 2018), dan (BovedaLambie dan Lambeth, 2018).

\subsection{Perilaku Konsumtif}

Menurut Dharmmesta dan Handoko (2011) menyatakan bahwa dalam mendeskripsikan perilaku konsumtif maka konsumen tidak dapat lagi membedakan antara kebutuhan dan keinginan yang belum terpenuhi atau terpuaskan. Kebutuhan yang dipenuhi bukan merupakan kebutuhan yang utama melainkan kebutuhan yang hanya sekedar mengikuti arus mode, ingin mencoba produk baru, ingin memperoleh pengakuan sosial, tanpa memperdulikan apakah memang dibutuhkan atau tidak. Konsep perilaku konsumtif sangat variatif, tetapi pada intinya pengertian perilaku konsumtif adalah membeli barang tanpa pertimbangan rasional atau bukan atas dasar kebutuhan pokok.

Enrich Fromm dalam Miranda (2017) dan Sumartono (2002) merumuskan beberapa indikator dalam perilaku konsumtif yaitu:

1. Pembelian karena iming-iming hadiah.

2. Pembelian karena kemasan menarik.

3. Pembelian untuk menjaga penampilan/gengsi.

4. Pembelian atas pertimbangan harga (bukan atas dasar manfaat atau kegunaannya).

5. Membeli produk hanya sekedar menjaga simbol status.

6. Pembelian karena adanya unsur konformitas terhadap model yang mengiklankan.

7. Munculnya penilaian bahwa membeli produk dengan harga mahal akan menimbulkan rasa percaya diri yang tinggi.

8. Mencoba lebih dari dua produk sejenis ( merk berbeda ).

\section{Metode Penelitian}

Jenis penelitian yang digunakan dalam penelitian ini adalah explanatory research atau penelitian penjelasan menggunakan pendekatan kuantitatif, dengan tingkat eksplanasi deskriptif (Suwarsito, Aliya, 2020). Menggunakan instrumen kuesioner sebagai alat pengumpulan data dan informasi utama dari responden. Penelitian ini menggunakan dua variabel yaitu variabel social media marketing sebagai variabel independen dan perilaku konsumtif sebagai variabel dependennya. Variabel independen social media marketing dikembangkan menjadi empat indikator yang terdiri dari product, price, place, dan promotion yang diuraikan menjadi 14 butir pertanyaan. Sedangkan variabel perilaku konsumtif dijabarkan menjadi delapan indikator, sehingga terdapat 22 butir pertanyaan dalam angket yang dianalisis.

Populasi dalam penelitian ini adalah wanita yang dapat dikategorikan sebagai wanita karir, yang bekerja dan berdomisili di Kota Pekanbaru serta menggunakan aplikasi Instagram sebagai salah satu media untuk berbelanja dan berada pada rentang usia 17-45 tahun. 
Sedangkan sampel diambil sebanyak 97 orang dengan metode non random sampling dengan teknik purposive sampling. Data tersebut kemudian akan dianalisis dengan analisis regresi linear sederhana dengan menggunakan SPSS.

\section{Hasil dan Pembahasan}

\subsection{Gambaran karakteristik responden}

Responden dalam penelitian ini terdiri dari para wanita karir yang mayoritas berusia 26 hingga 35 tahun yang tersebar di 12 Kecamatan di Kota Pekanbaru. Pekerjaan dominan responden merupakan karyawan kemudian selanjutnya PNS, wirausaha dan lainnya.

\subsection{Analisis Regresi Linear Sederhana}

Berdasarkan hasil penelitian, persamaan dalam analisis regresi linier sederhana dalam penelitian ini adalah:

Tabel 4.1. Uji Regresi Linier Sederhana Coefficients $^{\mathbf{a}}$

\begin{tabular}{|l|l|l|l|}
\hline \multirow{2}{*}{ Model } & \multicolumn{2}{|l|}{ Unstandardized Coefficients } & Standardized Coefficients \\
\cline { 2 - 4 } & \multicolumn{1}{|c|}{ B } & \multicolumn{1}{c|}{ Std. Error } & \multicolumn{1}{c|}{ Beta } \\
\hline \multirow{2}{*}{$\begin{array}{l}\text { (Constant) } \\
\text { Social Media Marketing ( X ) }\end{array}$} & 7.201 & 4.136 & .753 \\
\hline
\end{tabular}

a. Dependent Variable: Perilaku Konsumtif

Berdasarkan Tabel 4.1. tersebut dapat diketahui persamaan regresi sebagai berikut: Persamaan Regresi Sederhana: $\mathrm{Y}=7.201+0,838 \mathrm{X}+\mathrm{e}$. Artinya adalah apabila social media marketing diasumsikan bernilai nol (0), maka loyalitas pelanggan adalah tetap sebesar 7.201. Nilai koefisien regresi 0,838 menyatakan bahwa jika variabel social media marketing mengalami peningkatan 1 satuan, maka perilaku konsumtif akan mengalami peningkatan sebesar 0,838 . Artinya social media marketing mempunyai pengaruh yang positif terhadap perilaku konsumtif karena koefisien regresi variabel positif.

\subsection{Uji Hipotesis}

a. Uji Signifikan Parsial (Uji t)

\begin{tabular}{|c|c|c|c|c|c|c|}
\hline \multicolumn{7}{|c|}{$\begin{array}{c}\text { Tabel 4.2. Uji t } \\
\text { Coefficients }^{\mathrm{a}}\end{array}$} \\
\hline & \multirow{2}{*}{ Model } & \multicolumn{2}{|c|}{ Unstandardized Coefficients } & $\begin{array}{c}\text { Standardized } \\
\text { Coefficients }\end{array}$ & \multirow[t]{2}{*}{$\mathrm{T}$} & \multirow[t]{2}{*}{ Sig. } \\
\hline & & B & Std. Error & Beta & & \\
\hline 1 & $\begin{array}{l}\text { (Constant) } \\
\text { Social Media Marketing }\end{array}$ & $\begin{array}{l}7.201 \\
.838 \\
\end{array}$ & $\begin{array}{l}4.136 \\
.075\end{array}$ & .753 & $\begin{array}{l}1.741 \\
11.163\end{array}$ & $\begin{array}{l}.085 \\
.000\end{array}$ \\
\hline
\end{tabular}

a. Dependent Variable: Perilaku Konsumtif

Berdasarkan tabel 4.2. diatas maka dapat diketahui t hitung $(11.163)>\mathrm{t}$ tabel $(1,984)$ dan sig $(0,00)<(0,05)$ artinya variabel social media marketing berpengaruh secara signifikan terhadap perilaku konsumtif wanita karir di Kota Pekanbaru. 


\section{b. Uji Koefisien Korelasi}

Tabel 4.3. Koefisien Korelasi Model Summary ${ }^{b}$

\begin{tabular}{|l|l|l|l|l|}
\hline \multicolumn{1}{|c|}{ Model } & \multicolumn{1}{c|}{ R } & R Square & Adjusted R Square & Std. Error of the Estimate \\
\hline 1 & $.753^{\mathrm{a}}$ & .567 & .563 & 4.665 \\
\hline
\end{tabular}

a. Predictors: (Constant), Social Media Marketing

b. Dependent Variable: Perilaku Konsumtif

Dari tabel 4.3. diatas diatas dapat diketahui nilai $\mathrm{R}$ adalah 0,753 , yang berarti hubungan antara variabel independen (social media marketing) terhadap variabel dependent (Perilaku Konsumtif) sebesar 0,753 / 75,3\%, yang artinya hubungan korelasi kuat karena berada di rentang angka 0,60-0,799, dilihat berdasarkan penafsiran atau interpretasi angka korelasi antar 2 variabel yang dikemukakan oleh Sugiyono (2013).

\section{c. Uji Koefisien Determinasi $\left(\mathbf{R}^{2}\right)$}

Yaitu pengujian dengan kontribusi pengaruh dari semua variabel bebas secara bersama-sama terhadap variable tidak bebas. Dimana $\mathrm{R}^{2}$ nilainya adalah $0<\mathrm{R}^{2}<1$ semakin mendekati 1 nilai koefisien determinasinya $\left(\mathrm{R}^{2}\right)$ maka akan semakin kuat pengaruh antara kedua variable tersebut. Untuk lebih jelasnya dapat dilihat pada tabel 5.16 dibawah ini:

Tabel 4.4. Uji Koofesien Determinasi Model Summary ${ }^{\mathrm{b}}$

\begin{tabular}{|l|l|l|l|l|}
\hline Model & R & R Square & Adjusted R Square & Std. Error of the Estimate \\
\hline 1 & $.753^{\mathrm{a}}$ & .567 & .563 & 4.665 \\
\hline
\end{tabular}

a. Predictors: (Constant), Social Media Marketing

b. Dependent Variable: Perilaku Konsumtif

Dari tabel 4.4. diatas dapat diketahui nilai $\mathrm{R}$ Square adalah 0,567 yang berarti hubungan antara variabel independen (social media marketing) terhadap variabel dependen (perilaku ;onsumtif) sebesar 56,7\%. Berarti social media marketing dapat mempengaruhi perilaku konsumtif wanita karir di Kota Pekanbaru sebesar 56,7\% sementara sisanya sebesar 0,433 atau $43,3 \%$ dipengaruhi oleh variabel lain yang tidak digunakan dalam penelitian ini.

\section{Simpulan}

Berdasarkan hasil penelitian yang telah dilakukan mengenai pengaruh Instagram sebagai Social Media Marketing terhadap Perilaku Konsumtif Wanita Karir di Kota Pekanbaru, maka dapat disimpulkan bahwa Instagram sebagai Social Media Marketing (X) memiliki pengaruh signifikan terhadap Perilaku Konsumtif Wanita Karir di Kota Pekanbaru yaitu sebesar 56,7\%. Hal ini didukung dengan realitas peningkatan penggunaan media sosial sebagai sarana pemasaran terkini yang digunakan oleh pemasar.

Hasil penelitian ini juga mendukung penelitian sebelumnya yang dilakukan oleh ( Mohommad Rizki Efendi, Sri Wahyuni, Mukhamad Zulianto 2018) yang berjudul "Pengaruh signifikan Facebook sebagai social media marketing terhadap perilaku konsumtif mahasiswa Pendidikan Ekonomi, FKIP, Universitas Jember". Penelitian tersebut menunjukkan bahwa variabel Facebook sebagai social media marketing memiliki pengaruh yang signifikan terhadap perilaku konsumtif mahasiswa Pendidikan Ekonomi, FKIP, Universitas Jember. Dari penelitian tersebut diperoleh bahwa Social media marketing berpengaruh terhadap 
perilaku konsumtif dan di dukung oleh teori yang telah dikemukakan oleh (Boer, 2014), (Scheinbaum, 2018), dan (Boveda-Lambie dan Lambeth, 2018).

\section{Daftar Pustaka}

Barnes, S. (2015). Like, Follow, Share: Awesome, Actionable Social Media Marketing to Maximize Your Online Potential. Tycho Press. California

Baudrillard, J. (2017). The Consumer Society: Myths and Structures, Revised Edition. SAGE Publications Ltd. California.

Boer, K. M. (2014). Fenomena Situs Belanja Online Terhadap Pembentukan Karakter Konsumtif. Dalam Cyberspace and Culture: Melihat Dinamika Budaya Konsumerisme, Gaya Hidup, dan Identitas dalam Dunia Cyber. Editor F. G. Sukmono. Buku Litera. Yogyakarta.

Boveda-Lambie., A. \& K. G, Lambeth. (2018). Being Yourself Online: Why Facebook Users Display Their Desired Self. Dalam The Dark Side of Social Media: A Consumer Psychology Perspective. Editor A. C. Scheinbaum. Routledge. New York.

Dharmmesta, B.S dan Handoko, H. (2011). Manajemen Pemasaran-Analisis Perilaku Konsumen. BPFE. Yogyakarta.

Efendi, M. R., Wahyuni, S., Dan Zulianto, M. (2018). Pengaruh Facebook Sebagai Social Media Marketing terhadap perilaku konsumtif mahasiswa. Jurnal Pendidikan Ekonomi. 12 (1): 8292.

Gurnelius, S. (2011). 30-Minute Social Media Marketing. McGraw-Hill. USA.

Khan, A. S. dan Jan, F. (2015). The Study of Organization Commitment and Job Satisfaction among Hospital Nurses. A Survey of District Hospitals of Dera Ismail Khan. Global Journal of Management and Business Research: A Administration and Management, Vol 15(1).

Miranda, S. (2017). Pengaruh Instagram Sebagai Media Online Shopping Fashion Terhadap Perilaku Konsumtif Mahasiswi Fakultas Ilmu Sosial dan Ilmu Politik Universitas Riau. JOM FISIP. 4(1): $1-15$.

Scheinbaum, A. C. (2018). A Framework for the Dark Side of Social Media: From Digital Drama to Digital Over Engagement. Dalam The Dark Side of Social Media: A Consumer Psychology Perspective. Editor A. C. Scheinbaum. Routledge. New York.

Sumartono. (2002). Terperangkap dalam Iklan. Alfabeta. Bandung.

Suwarsito, S., \& Aliya, S. (2020). Kualitas Layanan Dan Kepuasan Serta Pengaruhnya Terhadap Loyalitas Pelanggan. Jurnal Ilmiah Bina Manajemen, 3(1), 27-35

Yulistara, A. (2013, juni 21). Ini Sebabnya Wanita Lebih Suka Belanja Ketimbang Pria. Retrieved Mei 30, 2015, Wolipop:http://wolipop.detik.com/read/2013/06/21/083511/2279764/1141/ini sebabnya-wanita-lebih-sukabelanja-ketimbang-pria.

Zarella, D. (2010). The Social Media Markeitng Books. PT Serambi Ilmu Semesta. Jakarta

https.//www.statista.com/statistics/272014/global-social-network-ranked-by-number-of-users

(Diakses pada 19 Februari 2019)

http://sabilfeb.lecture.ub.ac.id/files/2014/03/social-marketing-final.pdf.

(Diakses pada 4 Februari 2019). 